Supporting Information for:

\title{
Single-Fluorophore Single-Chain Nanoparticle Undergoes Fluorophore-Driven Assembly with Fluorescence Features Retained in Physiological Milieu
}

\author{
Sijia Liu, Jie Rong, Rui Liu, and Jonathan S. Lindsey* \\ jlindsey@ncsu.edu
}

Department of Chemistry, North Carolina State University, Raleigh, North Carolina 27695-8204

\section{Ionic Strength Equation}

The ionic strength was calculated by use of eq S1, where $c_{i}$ is the molar concentration of ion $i(\mathrm{M})$, and $z_{i}$ is the charge number of that ion.

$$
I=\frac{1}{2} \sum_{i=1}^{n} c_{i} z_{i}^{2}
$$

\section{Previous Polymers}

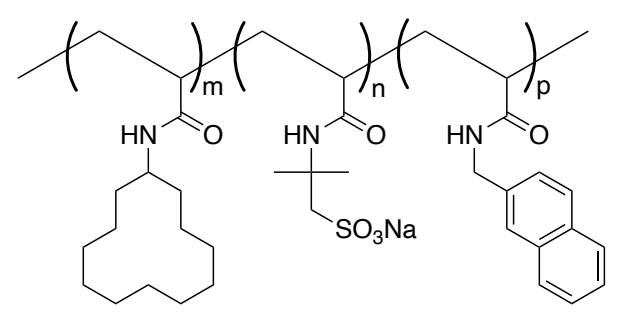

Chart S1. A polymer (from Kamachi and coworkers ${ }^{34}$ ) that contains cyclododecyl, sulfonate and fluorescent pendant groups, but without reactive terminal groups. 


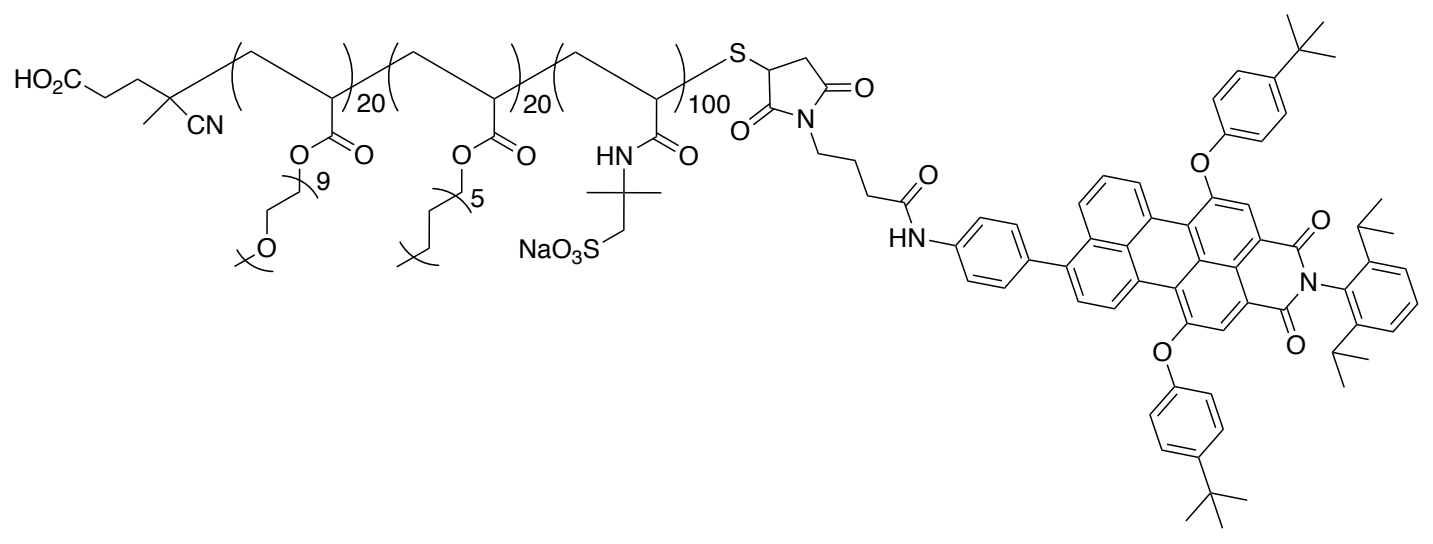

Chart S2. Structure of F-PMI. ${ }^{29}$

3. DLS Studies of the Polymers and Polymer-Fluorophore Conjugates

Ionic strength. DLS studies of F-Ph and $\mathbf{P S}_{5} \mathbf{C D}(\mathbf{2 8})$ were carried out in water and aqueous media containing various concentrations of $\mathrm{NaCl}(0.25 \mathrm{M}, 0.50 \mathrm{M}, 0.75 \mathrm{M}$ and $1.0 \mathrm{M})$. Both polymers afforded a unimer quantitatively in aqueous media containing $\geq 0.50 \mathrm{M} \mathrm{NaCl}$. 

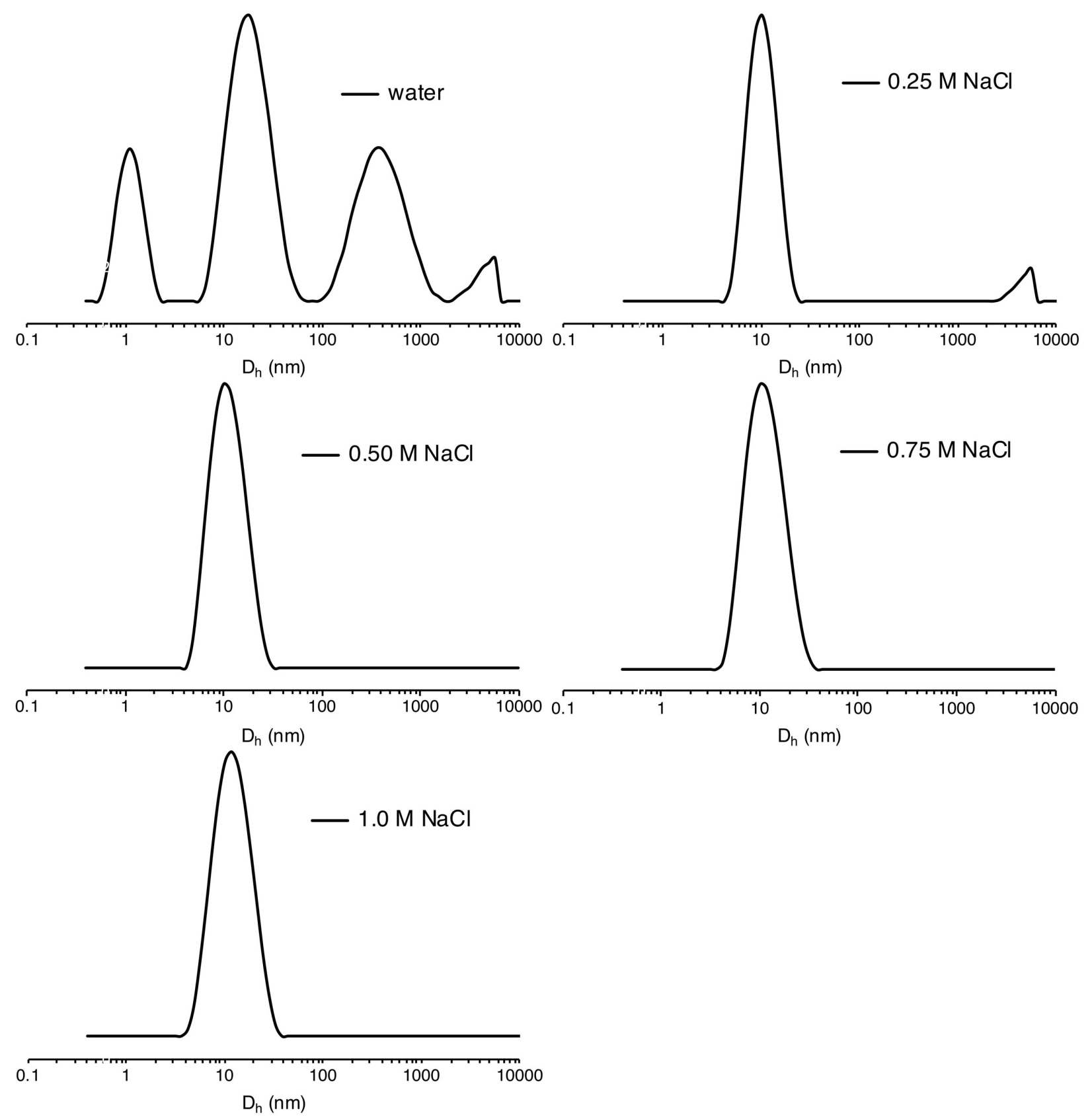

Figure S1. DLS data of $\mathbf{F}-\mathbf{P h}$ in aqueous $\mathrm{NaCl}$ solutions of varying concentration at room temperature. 

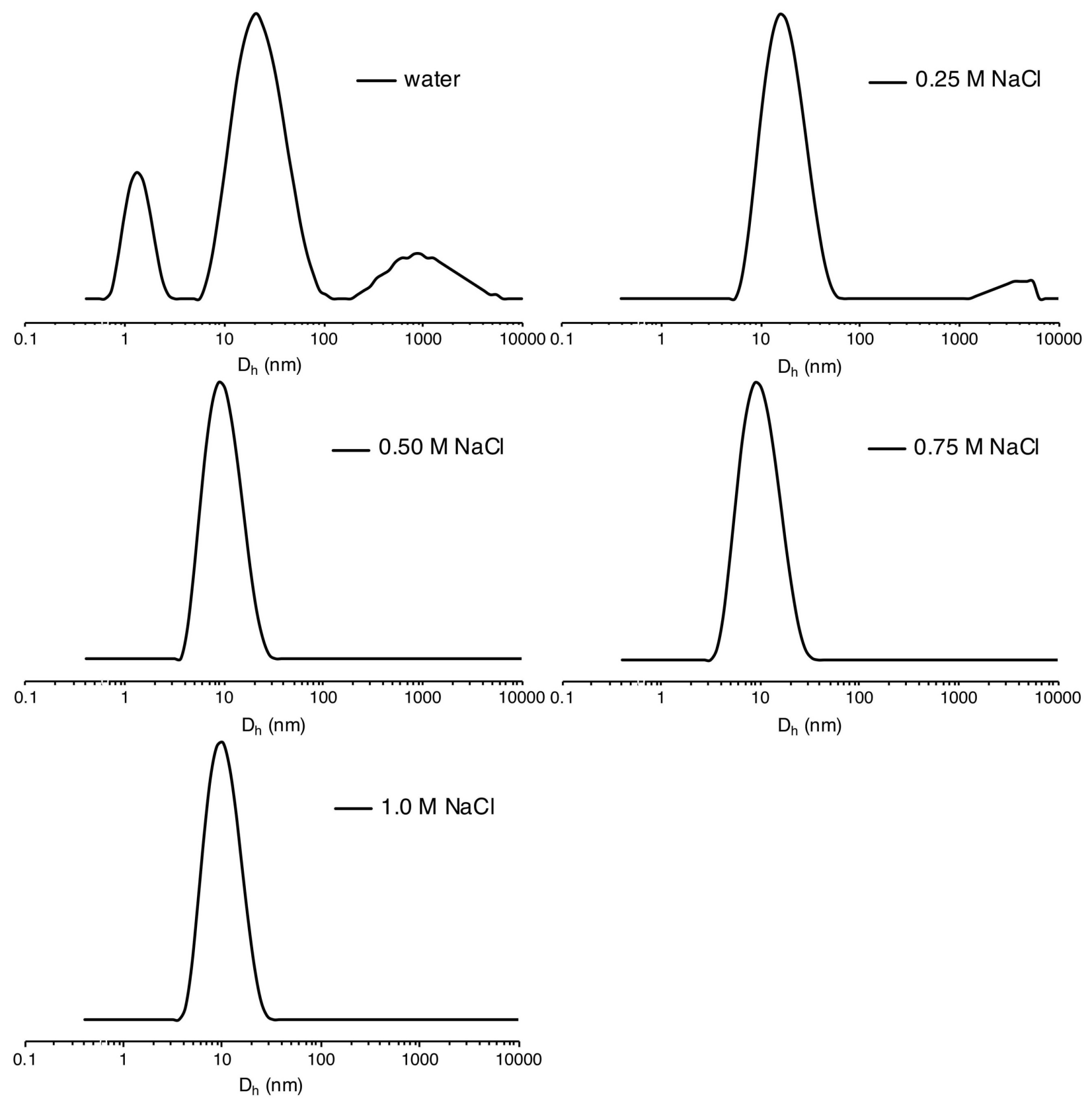

Figure S2. DLS data of $\mathbf{P S} \mathbf{S}_{\mathbf{5}} \mathbf{C D ( 2 8 )}$ in aqueous $\mathrm{NaCl}$ solutions at room temperature.

Summary of DLS studies of $\mathrm{PS}_{\mathrm{n}} \mathrm{CD}\left(\mathrm{M}_{\mathrm{w}}\right)$ polymers. Compared with previous polymer containing lauryl, PEG9 and sulfonate groups, which assemble unimerically with a specific ratio (lauryl : PEG9 : sulfonate $=1: 1: 5),{ }^{29}$ all $\mathbf{P S}_{\mathbf{n}} \mathbf{C D}\left(\mathbf{M}_{\mathbf{w}}\right)$ polymers exhibited a unimer quantitatively in $1 \mathrm{M}$ aqueous $\mathrm{NaCl}$ solution (Figure S3). In PBS solution, $\mathbf{P S}_{\mathbf{n}} \mathbf{C D}(\mathbf{M w}$ ) polymers (without a hydrophobic fluorophore) contained aggregated particles (Figure S4). Attachment to a hydrophobic fluorophore enabled $\mathbf{P S}_{\mathbf{n}} \mathbf{C D}\left(\mathbf{M}_{\mathbf{w}}\right)$ polymers with sufficient $\mathrm{M}_{\mathrm{W}}$ to assemble quantitatively into a unimeric particle without aggregation. DLS data of PS4CD(17)-PMI conjugates in PBS solution are shown in Figure S5, and DLS data of other polymer-PMI conjugates are shown in Figure 3. 

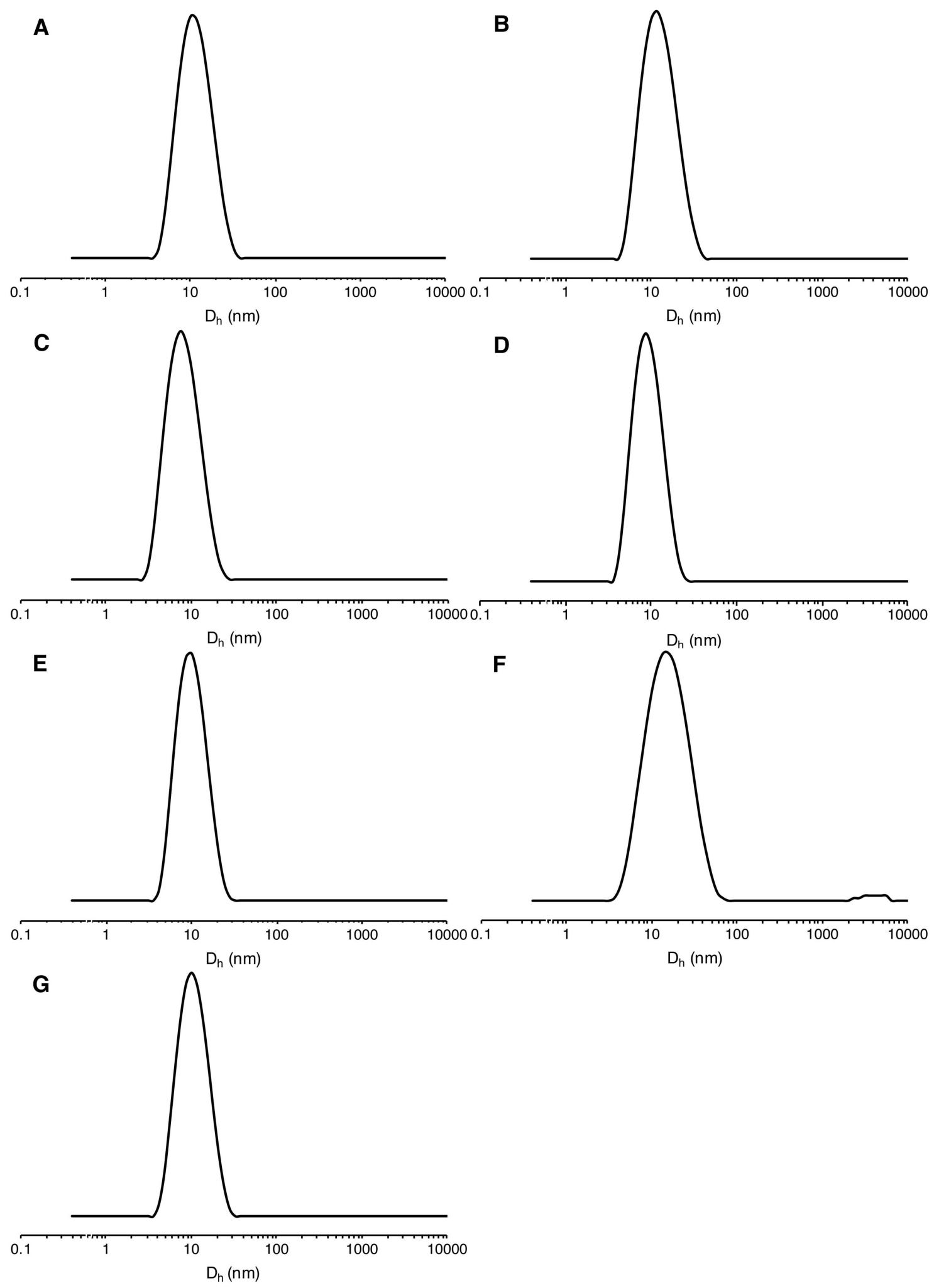

$\mathbf{F}$

Figure S3. DLS data of $\mathbf{P S}_{4} \mathbf{C D}(17)$ (panel A), $\mathbf{P S}_{4} \mathbf{C D}(26)$ (panel B), $\mathbf{P S}_{5} \mathbf{C D}(10)$ (panel C), $\mathbf{P S}_{5} \mathbf{C D}(18)$ (panel D), $\mathbf{P S}_{5} \mathbf{C D}(28)$ (panel E), $\mathbf{P S}_{5} \mathbf{C D}(34)$ (panel F) and $\mathbf{P S}_{6} \mathbf{C D}(28)$ (panel G) in 1 $\mathrm{M}$ aqueous $\mathrm{NaCl}$ solution at room temperature. 

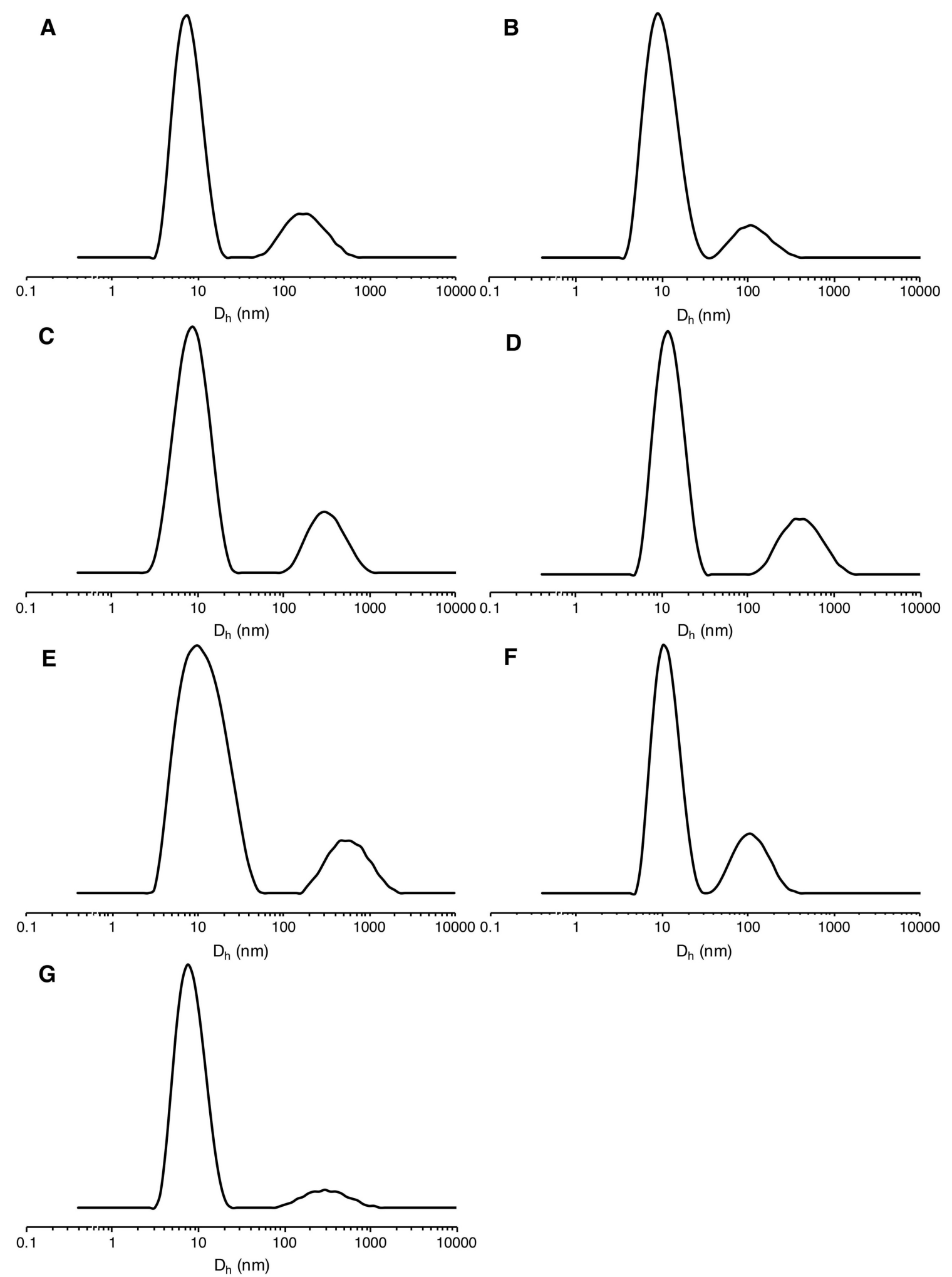

Figure S4. DLS data of $\mathbf{P S}_{4} \mathbf{C D}$ (17) (panel A), $\mathbf{P S}_{4} \mathbf{C D}$ (26) (panel B), $\mathbf{P S}_{5} \mathbf{C D}$ (10) (panel C), $\mathbf{P S}_{5} \mathbf{C D}$ (18) (panel D), $\mathbf{P S}_{5} \mathbf{C D}$ (28) (panel E), $\mathbf{P S}_{5} \mathbf{C D}(34)$ (panel F) and $\mathbf{P S}_{6} \mathbf{C D}(28)$ (panel G) in PBS solution at room temperature. 


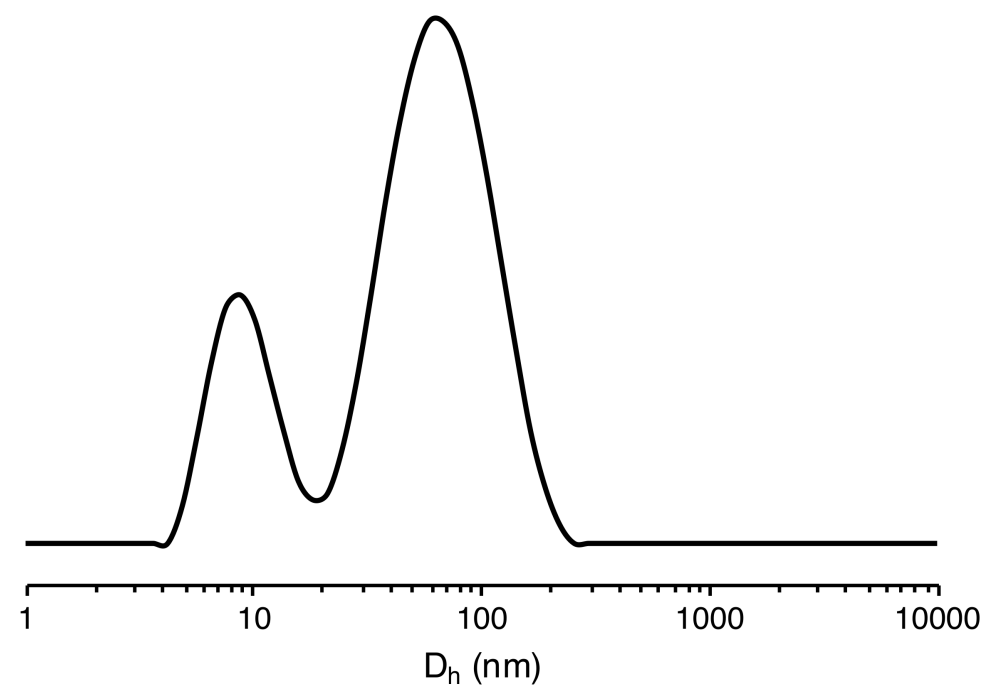

Figure S5. DLS data of $\mathbf{P S}_{\mathbf{4}} \mathbf{C D ( 1 7 ) - P M I}$ conjugates in PBS solution at room temperature. 
Statistical analysis. A statistical analysis for DLS spectroscopy was carried out pertaining to the results in Figure 4. Each polymer-PMI conjugate was examined five times by DLS spectroscopy. The results are shown in Figure $\mathrm{S} 6$. The mean and standard deviation of $\mathrm{D}_{\mathrm{h}}$ (unimer peak for $\mathbf{P S} \mathbf{S}_{5} \mathbf{C D}$ (10)-PMI and $\mathbf{P S}_{5} \mathbf{C D}$ (18)-PMI) also were calculated (Table S1).
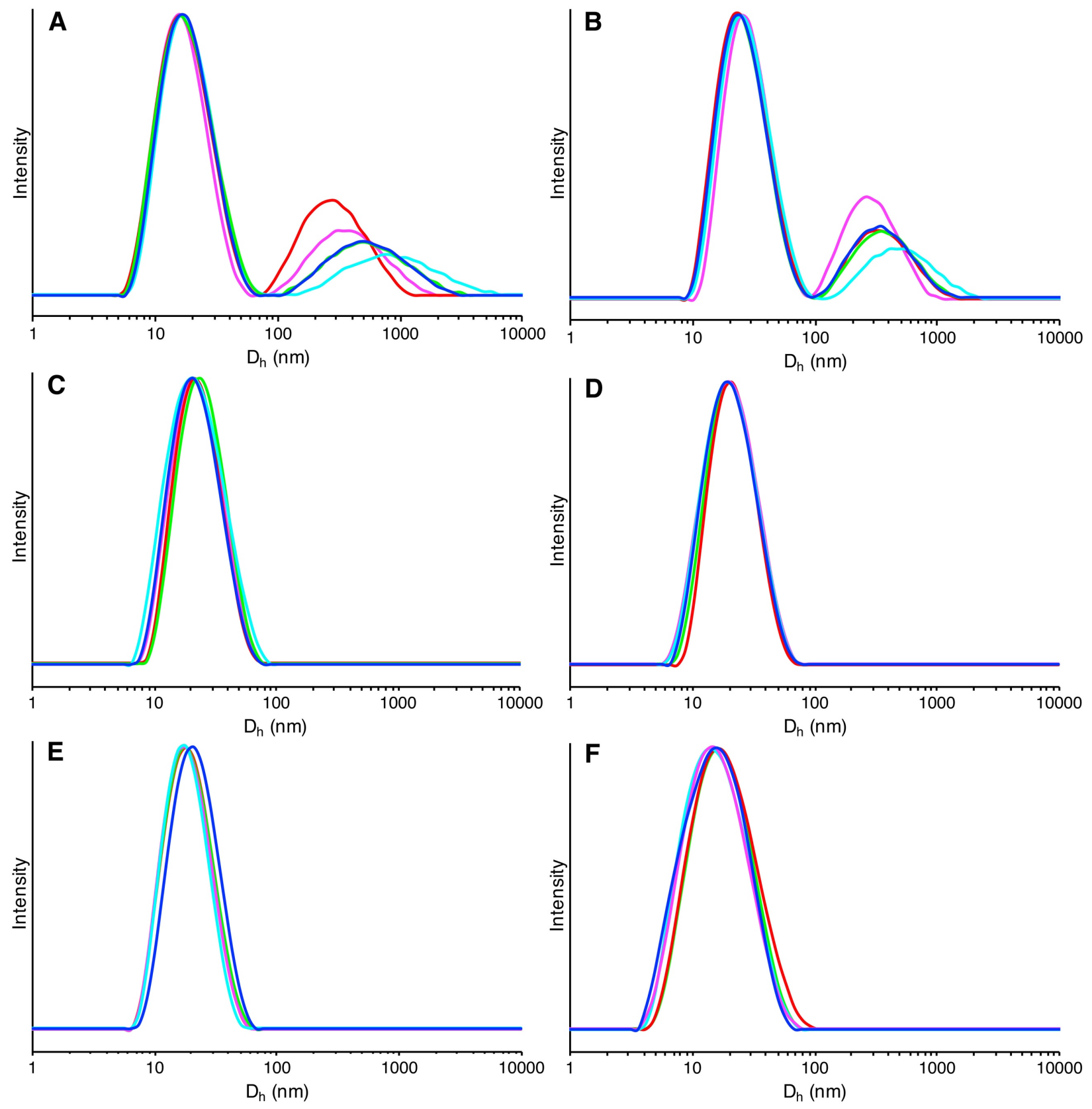

Figure S6. DLS data (5 times) in PBS solution at room temperature of the following polymers: PS $_{5} \mathbf{C D}$ (10)-PMI (panel A), PS 5 CD(18)-PMI (panel B), $\mathbf{P S}_{4} \mathbf{C D}$ (26)-PMI (panel C), PS $\mathbf{C D}$ (28)PMI (panel D), PS6 CD(28)-PMI (panel E) and PS5CD(34)-PMI (panel F). 
Table S1. Mean and standard deviation of repeated DLS results.

\begin{tabular}{|c|c|c|c|}
\hline Compounds & $\begin{array}{l}\text { Five times } \mathrm{D}_{\mathrm{h}}(\mathrm{nm}) \\
\text { (intensity) of unimer }\end{array}$ & Mean (nm) & $\begin{array}{c}\text { Standard deviation } \\
(\mathrm{nm})\end{array}$ \\
\hline \multirow{5}{*}{$\mathrm{PS}_{5} \mathrm{CD}(10)-\mathrm{PMI}$} & 18.75 & \multirow{5}{*}{19.36} & \multirow{5}{*}{0.39} \\
\hline & 19.96 & & \\
\hline & 19.51 & & \\
\hline & 19.30 & & \\
\hline & 19.30 & & \\
\hline \multirow{5}{*}{$\mathrm{PS}_{5} \mathrm{CD}(18)-\mathrm{PMI}$} & 29.31 & \multirow{5}{*}{27.97} & \multirow{5}{*}{0.97} \\
\hline & 27.28 & & \\
\hline & 27.19 & & \\
\hline & 28.99 & & \\
\hline & 27.06 & & \\
\hline \multirow{5}{*}{$\mathrm{PS}_{4} \mathrm{CD}(26)-\mathrm{PMI}$} & 24.35 & \multirow{5}{*}{24.68} & \multirow{5}{*}{0.90} \\
\hline & 24.58 & & \\
\hline & 26.32 & & \\
\hline & 24.58 & & \\
\hline & 23.57 & & \\
\hline \multirow{5}{*}{$\mathrm{PS}_{5} \mathrm{CD}(28)-\mathrm{PMI}$} & 23.00 & \multirow{5}{*}{22.58} & \multirow{5}{*}{0.40} \\
\hline & 23.14 & & \\
\hline & 22.29 & & \\
\hline & 22.21 & & \\
\hline & 22.27 & & \\
\hline \multirow{5}{*}{$\mathrm{PS}_{6} \mathrm{CD}(28)-\mathrm{PMI}$} & 20.64 & \multirow{5}{*}{21.13} & \multirow{5}{*}{1.45} \\
\hline & 22.83 & & \\
\hline & 19.32 & & \\
\hline & 22.83 & & \\
\hline & 20.03 & & \\
\hline \multirow{5}{*}{$\mathrm{PS}_{5} \mathrm{CD}(34)-\mathrm{PMI}$} & 19.53 & \multirow{5}{*}{18.73} & \multirow{5}{*}{1.34} \\
\hline & 21.00 & & \\
\hline & 17.87 & & \\
\hline & 17.78 & & \\
\hline & 17.47 & & \\
\hline
\end{tabular}




\section{Characterization of the Polymers}

All $\mathbf{P S}_{\mathbf{n}} \mathbf{C D}\left(\mathbf{M}_{\mathbf{w}}\right)$ polymers were examined by analytical SEC, ${ }^{1} \mathrm{H}$ NMR spectroscopy, DLS (results have been shown above) and absorption spectroscopy. The $\mathrm{M}_{\mathrm{w}}$ of each $\mathbf{P S}_{\mathbf{n}} \mathbf{C D}\left(\mathbf{M}_{\mathrm{w}}\right)$ polymer was inferred from analytical SEC (Figure S7). The molecular weight calibration curve was obtained by six standard poly(2-vinylpyridine) (PVP) samples. The $\mathrm{M}_{\mathrm{w}}$ values, $\mathrm{M}_{\mathrm{n}}$ values and polydispersity indexes (Table S2) were then calculated by the Agilent Cirrus gel permeation chromatography (GPC) software. 

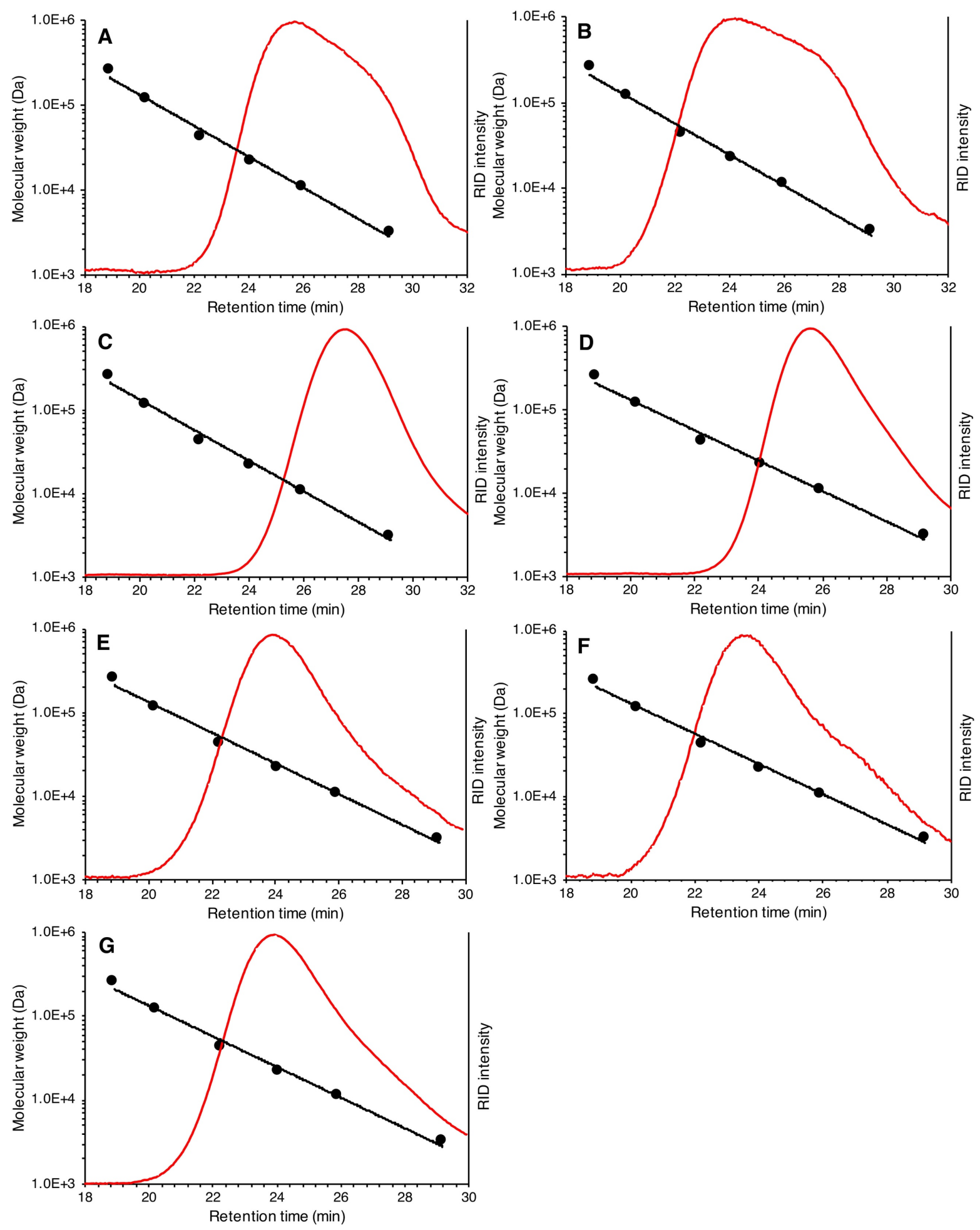

Figure S7. HPLC molecular weight calibration curve using polyvinyl pyridine (PVP) as standard (black line in all panels) eluting in HPLC-grade DMF (containing $50 \mathrm{mM} \mathrm{LiCl}$ ) at $50^{\circ} \mathrm{C}$ with flow rate of $0.8 \mathrm{~mL} / \mathrm{min}$. Analytical $\mathrm{SEC}$ data of $\mathbf{P S}_{4} \mathbf{C D}$ (17) (panel A), $\mathbf{P S}_{4} \mathbf{C D}$ (26) (panel B), $\mathbf{P S}_{5} \mathbf{C D}$ (10) (panel C), $\mathbf{P S}_{5} \mathbf{C D}$ (18) (panel D), $\mathbf{P S}_{5} \mathbf{C D}(28)$ (panel E), PS 5 CD(34) (panel F) and $\mathbf{P S}_{6} \mathbf{C D}(28)$ (panel G) eluting in HPLC-grade DMF (containing $50 \mathrm{mM} \mathrm{LiCl}$ ) at $50{ }^{\circ} \mathrm{C}$ with flow rate of $0.8 \mathrm{~mL} / \mathrm{min}$ by refractive index detector (red curves). 
Table S2. The Mw, Mn and polydispersity indexes of $\mathbf{P S}_{\mathbf{n}} \mathbf{C D}\left(\mathbf{M}_{\mathbf{w}}\right)$ polymers.

\begin{tabular}{|c|c|c|c|c|}
\hline Polymer name & $\begin{array}{c}\text { Theoretical } \\
\text { molecular weights }\end{array}$ & $\mathrm{M}_{\mathrm{W}}$ & $\mathrm{M}_{\mathrm{n}}$ & $\begin{array}{l}\text { Polydispersity } \\
\text { index }\end{array}$ \\
\hline $\mathrm{PS}_{4} \mathrm{CD}(17)$ & $23.8 \mathrm{kDa}$ & $17 \mathrm{kDa}$ & $9.0 \mathrm{kDa}$ & 1.9 \\
\hline $\mathrm{PS}_{4} \mathrm{CD}(26)$ & $58.5 \mathrm{kDa}$ & $26 \mathrm{kDa}$ & $15 \mathrm{kDa}$ & 1.7 \\
\hline $\mathrm{PS}_{5} \mathrm{CD}(10)$ & $16.1 \mathrm{kDa}$ & $10 \mathrm{kDa}$ & $6.7 \mathrm{kDa}$ & 1.5 \\
\hline $\mathrm{PS}_{5} \mathrm{CD}(18)$ & $27.9 \mathrm{kDa}$ & $18 \mathrm{kDa}$ & $11 \mathrm{kDa}$ & 1.6 \\
\hline $\mathrm{PS}_{5} \mathrm{CD}(28)$ & $46.9 \mathrm{kDa}$ & $28 \mathrm{kDa}$ & $20 \mathrm{kDa}$ & 1.4 \\
\hline $\mathrm{PS}_{5} \mathrm{CD}(34)$ & $139.1 \mathrm{kDa}$ & $34 \mathrm{kDa}$ & $21 \mathrm{kDa}$ & 1.6 \\
\hline $\mathrm{PS}_{6} \mathrm{CD}(28)$ & $44.7 \mathrm{kDa}$ & $28 \mathrm{kDa}$ & 17 kDa & 1.7 \\
\hline
\end{tabular}

The characteristic peak of monomer CDA (5.12-5.07, $\mathrm{m}, 1 \mathrm{H}$, in $\mathrm{CDCl}_{3}$ ) and AMPS (3.20, $\mathrm{s}, 2 \mathrm{H}$, in $\mathrm{CD}_{3} \mathrm{OD}$ ) are shown in Figure $\mathrm{S} 8$ and Figure $\mathrm{S}$, respectively. The ratio of pendant groups of each $\mathbf{P S}_{\mathbf{n}} \mathbf{C D}\left(\mathbf{M}_{\mathbf{w}}\right)$ polymer was estimated by comparison of the results upon ${ }^{1} \mathrm{H} \mathrm{NMR}$ integration of characteristic peaks. The molecular weight could not be confirmed by ${ }^{1} \mathrm{H}$ NMR spectroscopy due to the weak signal of the protons on the terminal phenyl ring. Thus, the integrations shown in Figure S10 only stand for the ratio of proton $\mathrm{H}^{\mathrm{a}}$ to proton $\mathrm{H}^{\mathrm{b}}$, instead of the exact numbers of the protons. Other protons in cyclododecyl, dimethyl protons in sulfonate and protons on the backbone afford resonances that overlap in the region between 1.0-2.5 ppm. 


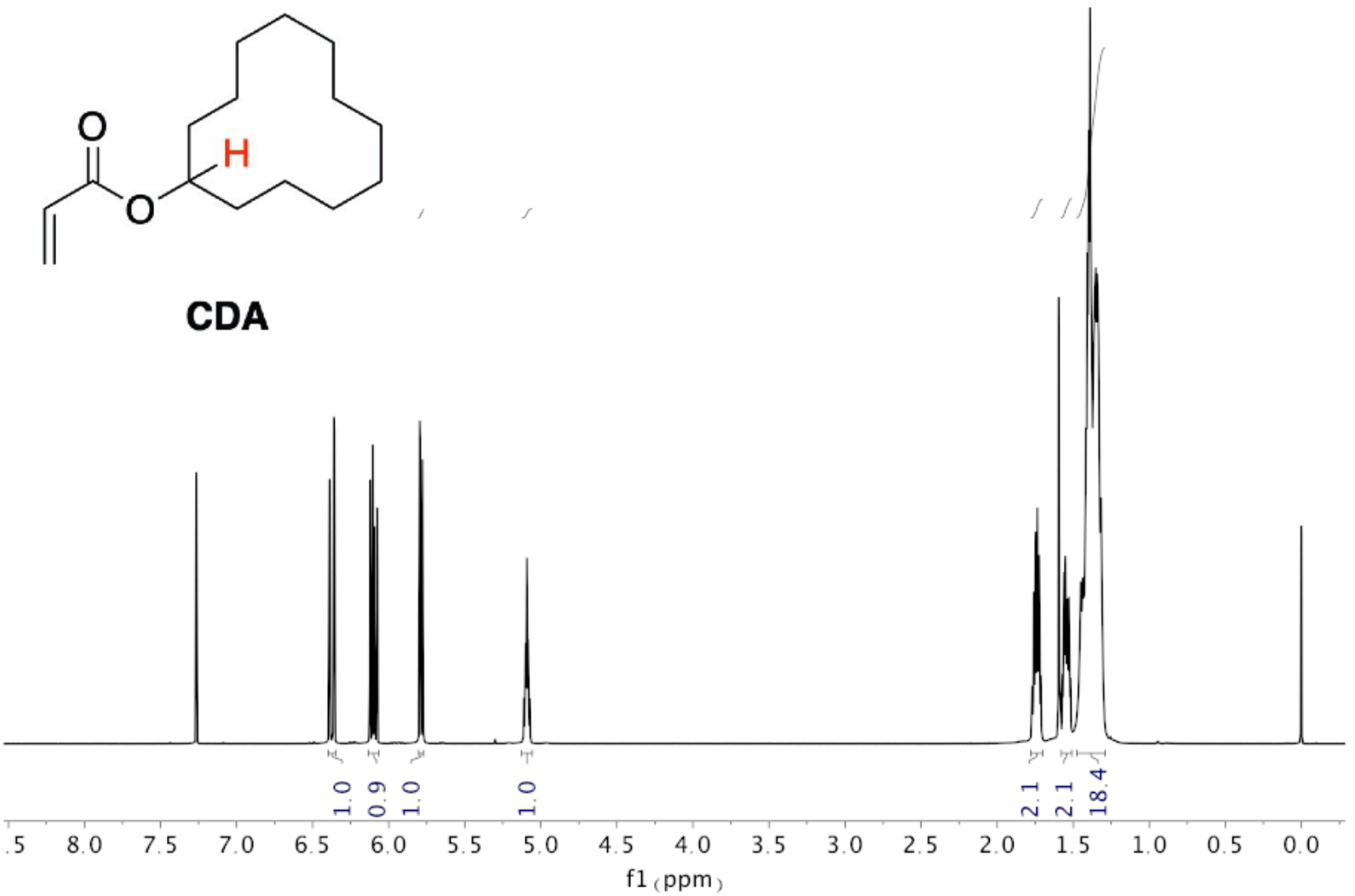

Figure S8. ${ }^{1} \mathrm{H}$ NMR spectrum of CDA in $\mathrm{CDCl}_{3}$.

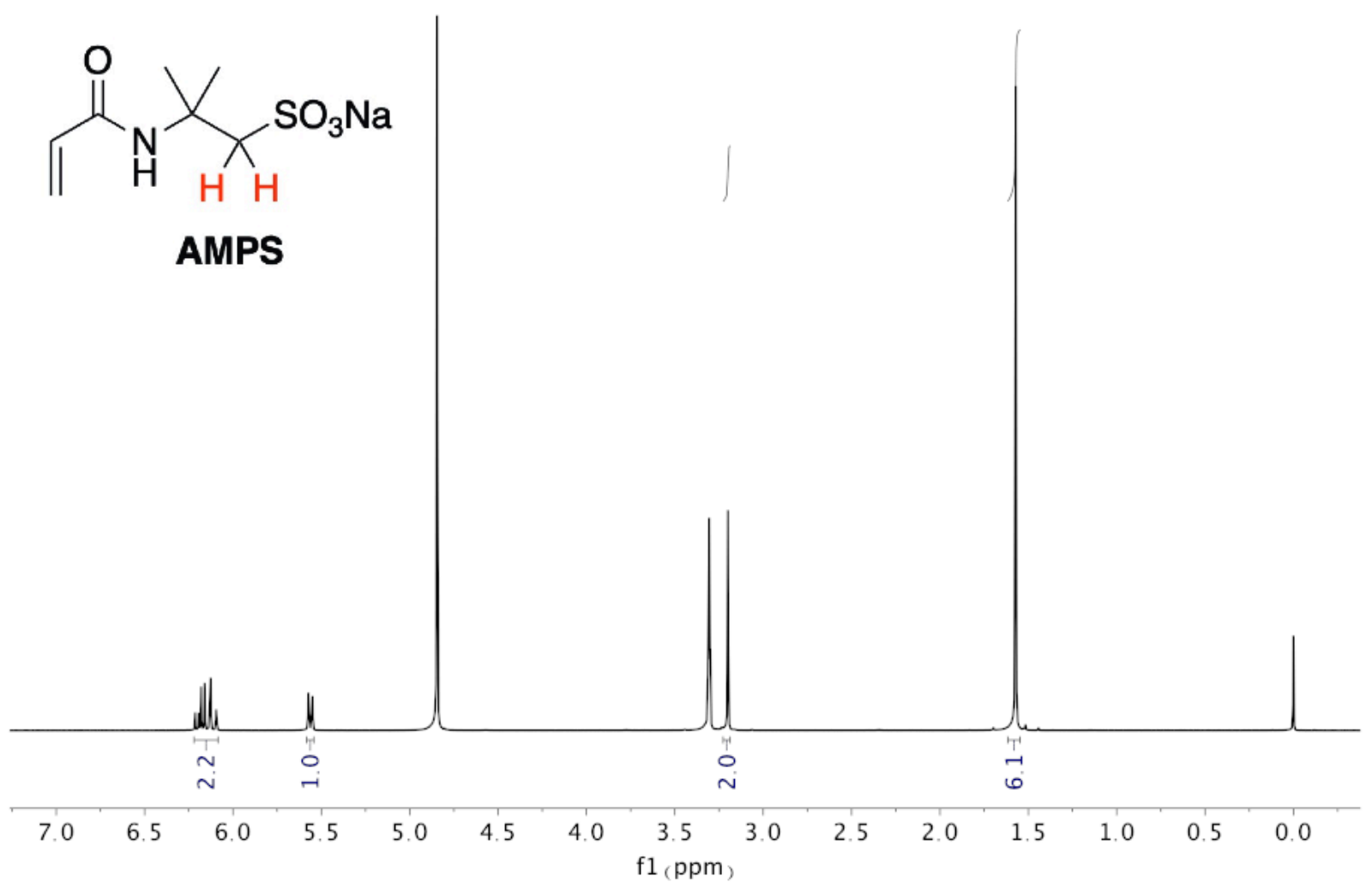

Figure S9. ${ }^{1} \mathrm{H}$ NMR spectrum of AMPS in $\mathrm{CD}_{3} \mathrm{OD}$. 

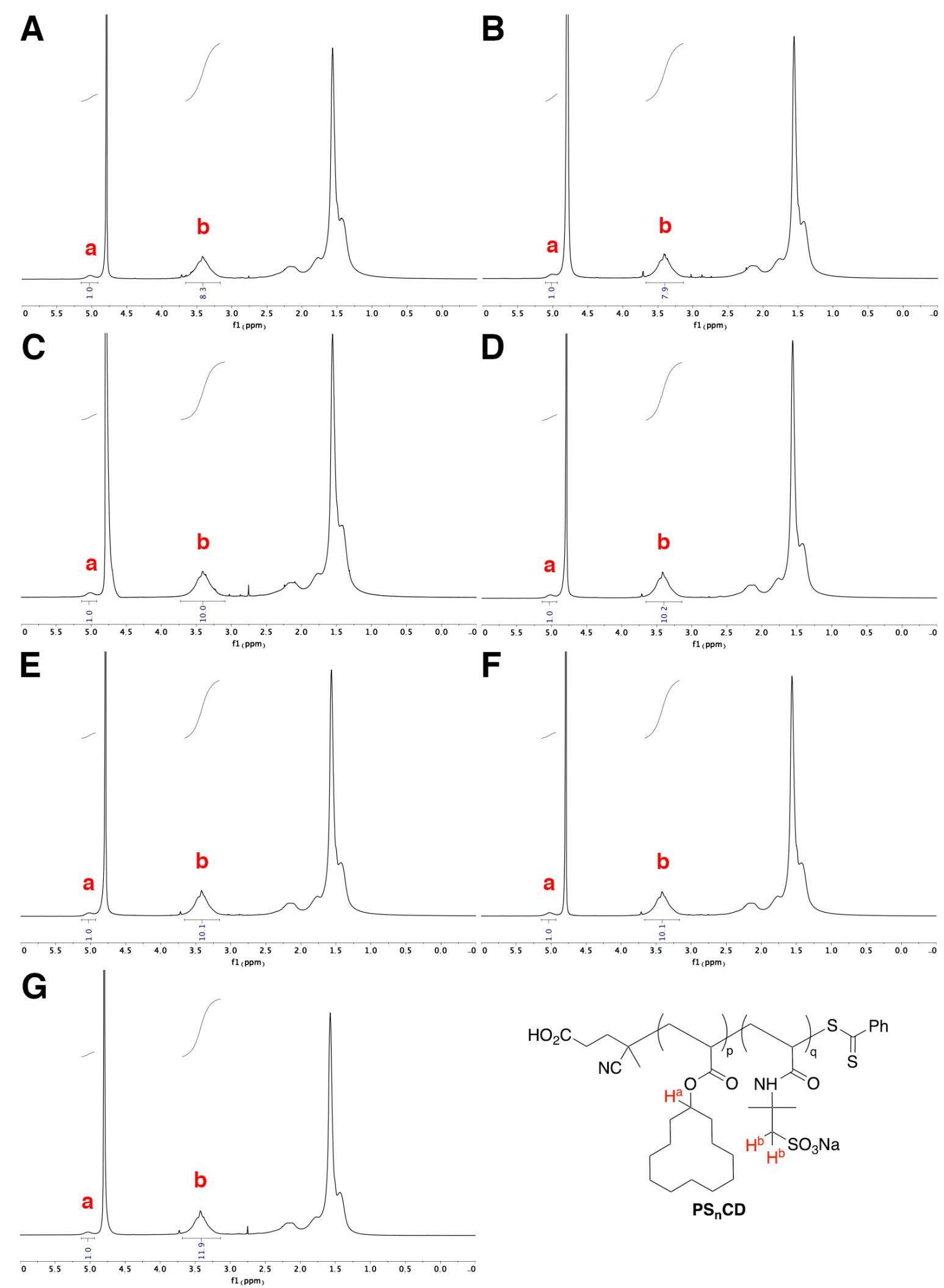

Figure S10. ${ }^{1} \mathrm{H}$ NMR spectra in $\mathrm{D}_{2} \mathrm{O}$ at $600 \mathrm{MHz}$ of $\mathbf{P S}_{4} \mathbf{C D}$ (17) (panel A), $\mathbf{P S}_{4} \mathbf{C D}$ (26) (panel B), $\mathbf{P S}_{5} \mathbf{C D}$ (10) (panel C), $\mathbf{P S}_{5} \mathbf{C D}(18)$ (panel D), $\mathbf{P S}_{5} \mathbf{C D}(28)$ (panel E), $\mathbf{P S}_{5} \mathbf{C D}(34)$ (panel F) and $\mathbf{P S}_{6} \mathbf{C D}(28)$ (panel G). 
The absorption spectra of $\mathbf{P S}_{\mathbf{n}} \mathbf{C D}(\mathbf{M w})$ polymers show a characteristic peak at $301 \mathrm{~nm}$ due chiefly to the dithiobenzoate moiety. Treatment with ethanolamine caused cleavage of the thiobenzoyl group to give a free thiol at the terminus $\left[\mathbf{P S}_{\mathbf{n}} \mathbf{C D}\left(\mathbf{M}_{\mathbf{w}}\right)-\mathbf{S H}\right]$. The absorption spectra of $\mathbf{P S}_{5} \mathbf{C D}(10)$ (before reaction) and $\mathbf{P S}_{5} \mathbf{C D}(10)-S H$ (after reaction and dialysis) are shown in Figure S11. The disappearance of characteristic absorption peak also indicated the complete conversion of the reaction.

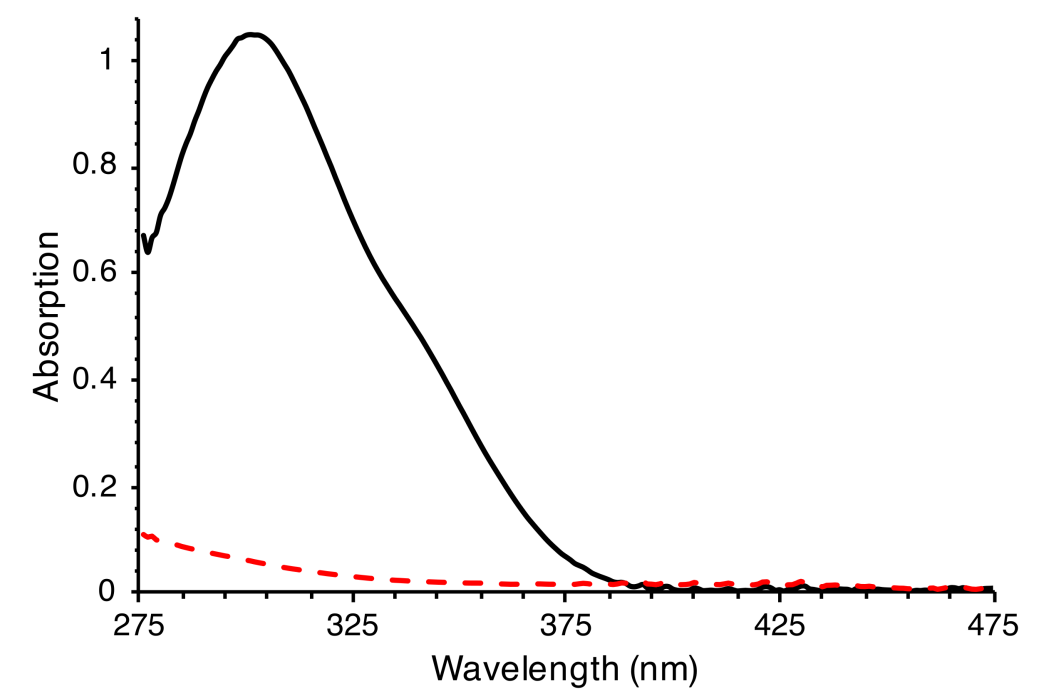

Figure S11. Absorption spectra of approximately equal concentrations of $\mathbf{P S}_{5} \mathbf{C D}$ (10) (black line) and $\mathbf{P S} \mathbf{5} \mathbf{C D ( 1 0 ) - S H}$ (red dashed line) in DMSO.

\section{Molar Absorption Coefficients}

The molar absorption coefficient of each of seven $\mathbf{P S}_{\mathbf{n}} \mathbf{C D}\left(\mathbf{M}_{\mathbf{w}}\right)-\mathbf{P M I}$ conjugates was measured in $\mathrm{H}_{2} \mathrm{O}$. The absorption of each $\mathbf{P S}_{\mathbf{n}} \mathbf{C D}\left(\mathbf{M}_{\mathbf{w}}\right)$-PMI conjugate over a range of concentrations $\left(6.25 \times 10^{-6} \mathrm{M}, 1.25 \times 10^{-5} \mathrm{M}, 1.88 \times 10^{-5} \mathrm{M}, 2.50 \times 10^{-5} \mathrm{M}\right.$, and $\left.3.13 \times 10^{-5} \mathrm{M}\right)$ in water (HPLC-grade) was measured at $527 \mathrm{~nm}$. The molar absorption coefficient (lowest: $2.95 \times 10^{4} \mathrm{M}^{-}$ ${ }^{1} \mathrm{~cm}^{-1}$, highest: $3.15 \times 10^{4} \mathrm{M}^{-1} \mathrm{~cm}^{-1}$ ) was derived from the slope of the curve (Figure S12, panel A$\mathrm{G})$. For $\mathbf{P S} \mathbf{S}_{5} \mathbf{C D}(\mathbf{2 8})-\mathbf{C H L}$, the measured molar absorption coefficient measured at $418 \mathrm{~nm}$ in PBS is $1.75 \times 10^{5} \mathrm{M}^{-1} \mathrm{~cm}^{-1}$ (Figure $\mathrm{S} 12$, panel $\mathrm{H}$ ). 

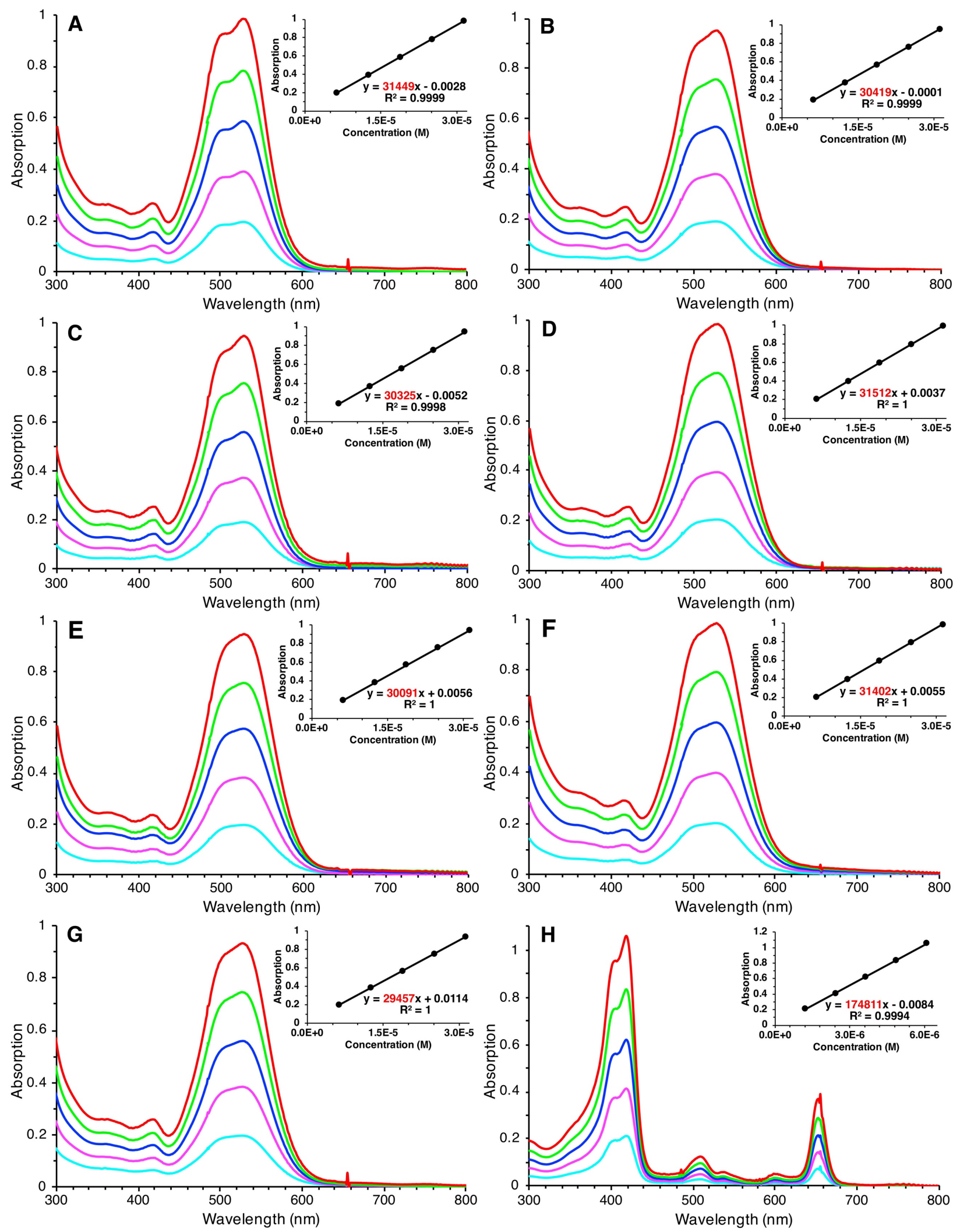

Figure S12. Absorption spectra in water at room temperature of $\mathbf{P S}_{4} \mathbf{C D}(17)-\mathrm{PMI}$ (panel A), $\mathbf{P S}_{4} \mathbf{C D}$ (26)-PMI (panel B), PS 5 CD(10)-PMI (panel C), PS 5 CD(18)-PMI (panel D), PS5 CD(28)PMI (panel E), PS 5 CD(34)-PMI (panel F), $\mathbf{P S}_{6} \mathbf{C D}$ (28)-PMI (panel G), and PS $5 \mathbf{C D ( 2 8 ) - C H L ~ ( i n ~}$ $\mathrm{PBS}$, panel $\mathrm{H}$ ) at different concentrations, and the corresponding calibration curves. 


\section{Pictures Concerning the Synthesis of $\operatorname{PS}_{\mathrm{n}} \mathrm{CD}\left(\mathrm{M}_{\mathrm{w}}\right)$.}

Before reaction, a mixture of CDA, AMPS, 1 and mesitylene was dissolved in DMF to give a red and clear solution. The mixture was deaerated by three freeze-pump-thaw cycles, treated with AIBN, and heated to $80{ }^{\circ} \mathrm{C}$ with stirring. The red solution gradually turned to yellow and precipitate apparently formed after $2 \mathrm{~h}$. After $24 \mathrm{~h}$, a yellow solution was obtained containing precipitate. The color change and precipitate formation process are shown in Figure S13.

Diethyl ether was poured into the reaction mixture to yield an extensive light-yellow precipitate (Figure S14, panel A). The precipitate was isolated by filtration (Figure S14, panel B), and then dissolved in water. The resulting yellow solution (Figure S14, panel C) was dialyzed in water for $24 \mathrm{~h}$. The resulting dialyzed solution was nearly colorless (Figure S14, panel D). The colorless solution was freeze-dried to afford a pink $\mathbf{P S}_{\mathbf{n}} \mathbf{C D}\left(\mathbf{M}_{\mathrm{w}}\right)$ solid. Several $\mathbf{P S}_{\mathbf{n}} \mathbf{C D}\left(\mathbf{M}_{\mathrm{w}}\right)$ polymers are shown in Figure S15.

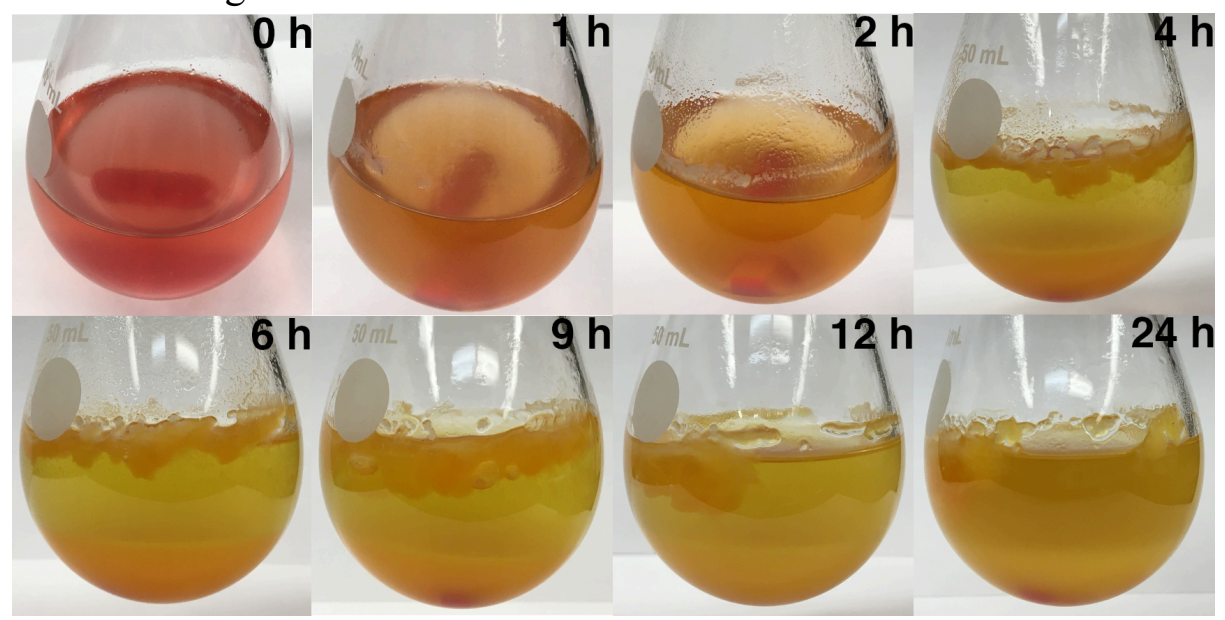

Figure S13. Color changes and precipitate formation during the synthesis of $\mathbf{P S}_{\mathbf{n}} \mathbf{C D}\left(\mathbf{M}_{\mathbf{w}}\right)$ polymers.

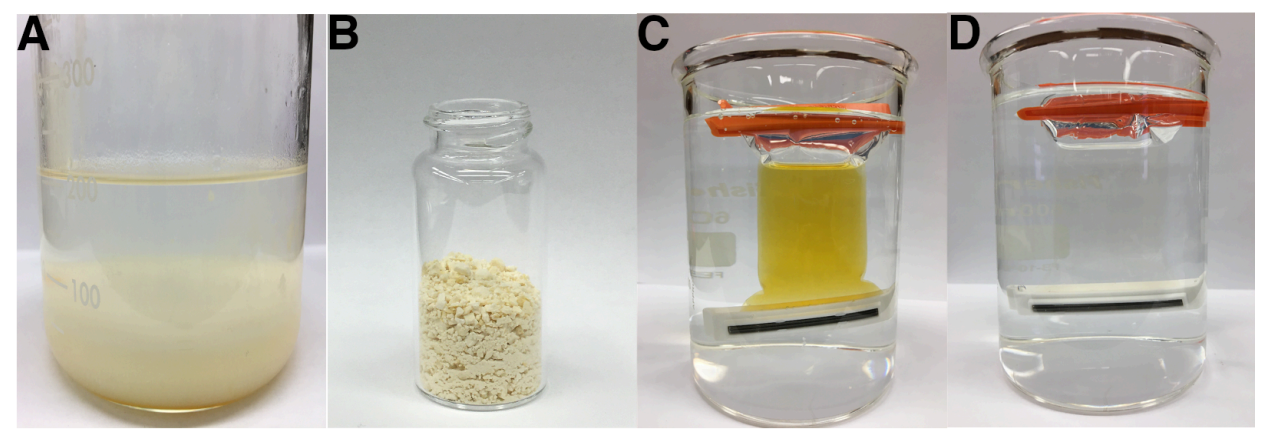

Figure S14. The purification process for polymers $\mathbf{P S}_{\mathbf{n}} \mathbf{C D}\left(\mathbf{M}_{\mathrm{w}}\right)$. (A) Reaction mixture following the addition of diethyl ether. (B) Dried powder following filtration. (C) Solution during initial dialysis in water. (D) Solution after extensive dialysis in water. 


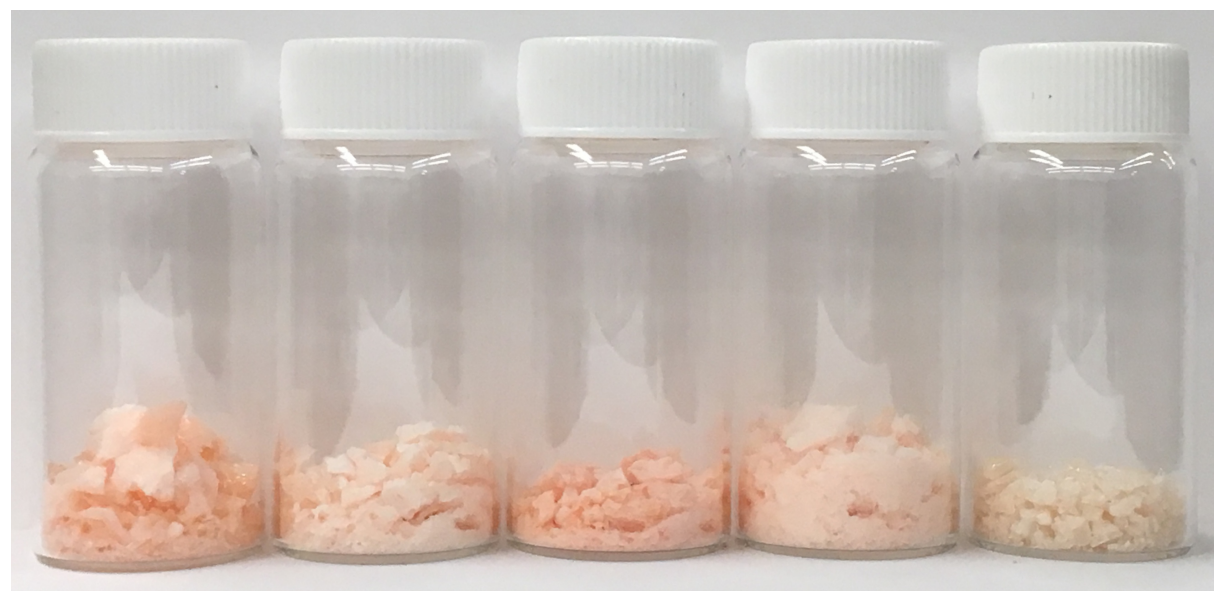

Figure S15. Some dialyzed and freeze-dried $\mathbf{P S}_{\mathbf{n}} \mathbf{C D}\left(\mathbf{M}_{\mathbf{w}}\right)$ polymers. 


\section{7. ${ }^{1}$ H NMR Spectral Data}

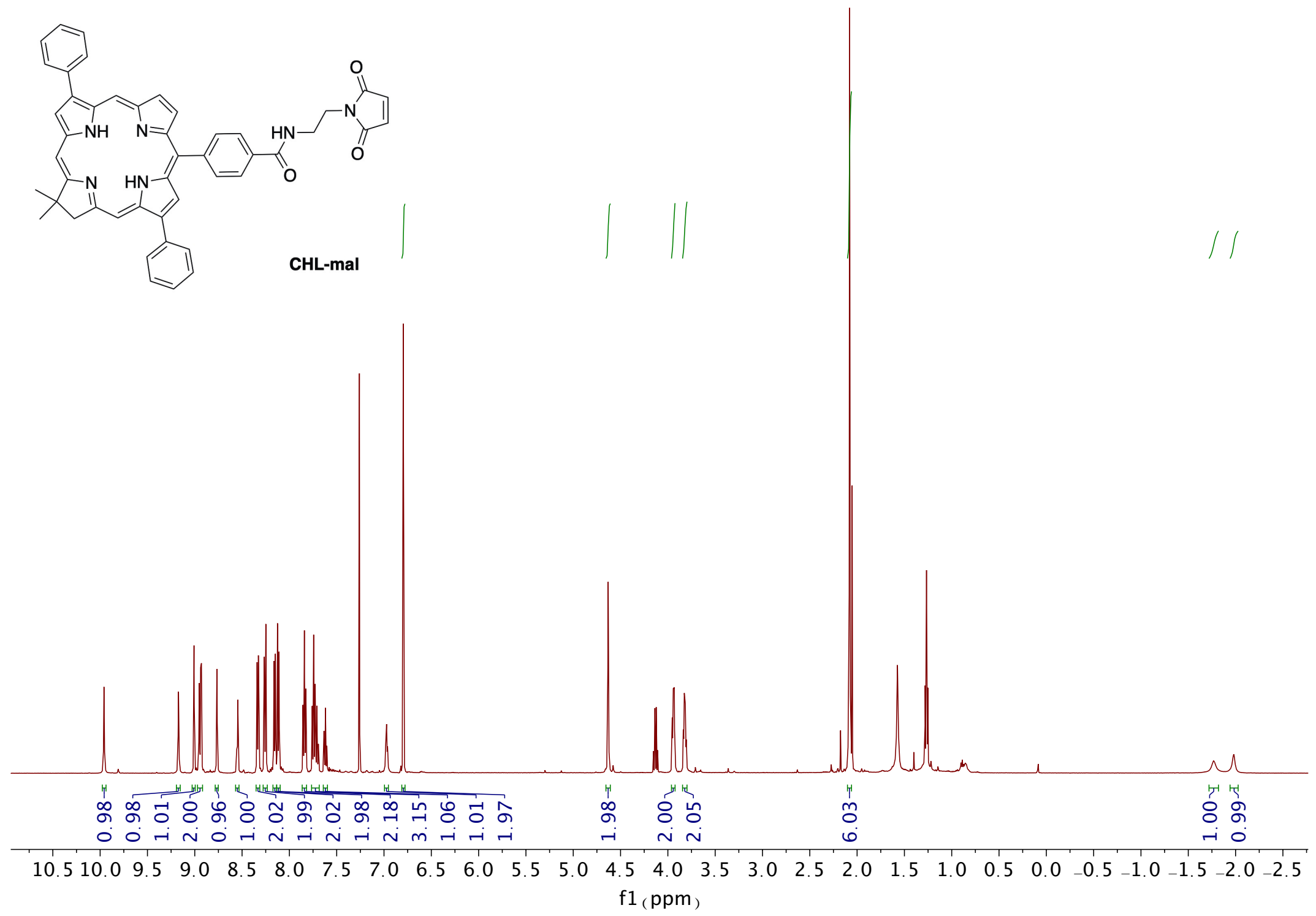




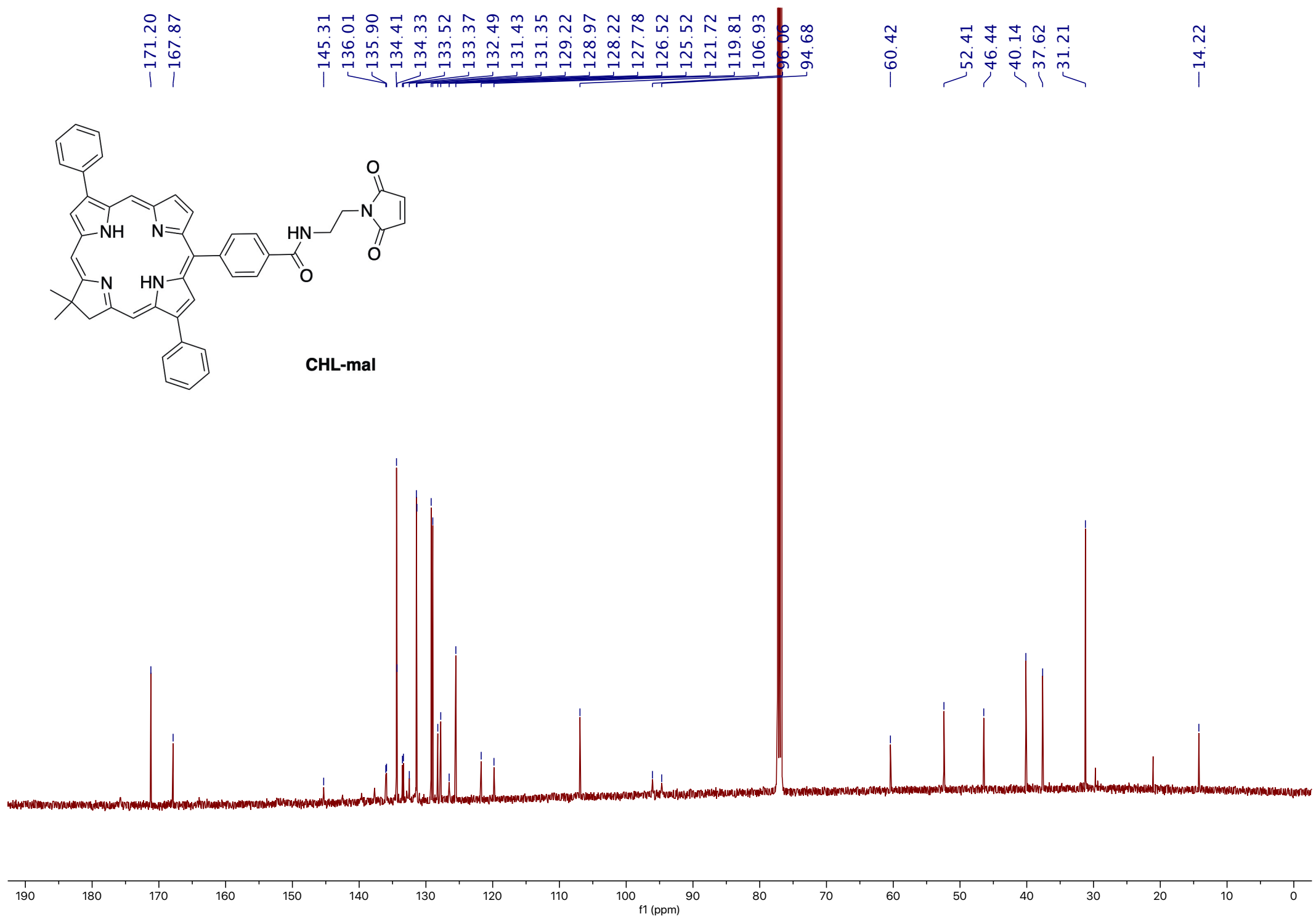

S20 